\title{
Analysis of Factors Related to Exclusive Breastfeeding Among Working Mother in The Area of Sungai Ulin Community Health Center, Banjarbaru City
}

\author{
Erni Wiliyani ZM ${ }^{*}$, Roselina Panghiyangani ${ }^{\text {*** }}$, Lenie Marlinae ${ }^{* * * *}$, Husaini $^{*}$, Meitria Syahadatina Noor ${ }^{\text {***** }}$ \\ * Master of Public Health, Faculty of Medicine, Lambung Mangkurat University, Indonesia \\ *** Department of Biomedicine, Faculty of Medicine, Lambung Mangkurat University, Indonesia \\ **** Public Health Study Program, Faculty of Medicine, Lambung Mangkurat University, Indonesia \\ ${ }^{* * * * *}$ Department of Public Health, Faculty of Medicine, Lambung Mangkurat University, Indonesia
}

DOI: 10.29322/IJSRP.10.08.2020.p104123

http://dx.doi.org/10.29322/IJSRP.10.08.2020.p104123

\begin{abstract}
The prevalence of exclusive breastfeeding coverage in Banjarbaru City is still low at $47.8 \%$, and one of the areas contributing to the low achievement is the Sungai Ulin Community Health Center working area with an achievement rate of only $17.8 \%$ in 2016 . The achievement is influenced by several factors; one of them is the condition of the working mother that can hamper the implementation of exclusive breastfeeding. This research aims to analyze factors related to exclusive breastfeeding in the work area of the Sungai Ulin Community Health Center in Banjarbaru City. This study uses a cross-sectional design with a random sampling technique. Respondents were working mothers who had babies aged 7 months to 12 months totaling 61 respondents. Data were analyzed using chi-square and Fisher exact tests for bivariate and binary logistic regression tests for multivariate. Based on data analysis using chi square and Fisher exact tests, it is known that knowledge (p-value: 0.032; PR: 3.14) and parity (p-value: 0.032 ; OPR: 3.14 ) are each related to exclusive breastfeeding. While the place and birth attendants ( $\mathrm{p}-$ value 0.475 ) and age (p-value: 0.099 ) are not related. Multivariate analysis results show that the number of children is the most dominant factor in exclusive breastfeeding (p-value 0.002, exp (B) 11.049). The most dominant factor about exclusive breastfeeding status is parity (p-value 0.002, exp (B) 11.049), which, if explored further, is related to the success of previous experiences in breastfeeding. Therefore, it is expected for the health sector, especially the community Health Center to encourage working mothers to be able to successfully implement exclusive breastfeeding, especially at the time of the birth of their first child
\end{abstract}

Index Terms- exclusive breastfeeding, working mother, age, knowledge, place and childbirth assistance, parity

\section{INTRODUCTION}

$\mathrm{T}$ he World Health Organization (WHO) and the United Nation Children Found (UNICEF) jointly recommend that babies should be given exclusive breastfeeding until they are 6 months old, then continue breastfeeding for up to two years of life (WHO, 2009). In Indonesia, the recommendation to breastfeeding for 6 months of birth has been regulated through several government regulations. Even so, in reality, not all mothers can exclusively breastfeed their babies (Haryani, 2014).

Achievements of exclusive breastfeeding coverage in Indonesia experience a downward trend. Data from the Indonesia Health Profile in 2015 amounted to $55.7 \%$ and decreased to $54 \%$ in 2016 and $46.74 \%$ in 2017 . Although higher than the national figure, exclusive breastfeeding coverage in South Kalimantan is also experiencing a downward trend. Data showed $61.4 \%$ coverage in 2015 and became 57.7\% and 53.68\% in 2016 and 2017 (South Kalimantan Provincial Health Office, 2018). Information obtained from the Ministry of Health is also known that South Kalimantan ranks 19th out of 33 provinces in Indonesia. Banjarbaru City ranks fourth in terms of low coverage of exclusive breastfeeding until August 2017. These achievements were recorded at only $47.78 \%$. From the 8 community Health Center in Banjarbaru City, the lowest exclusive breastfeeding coverage was in the working area of Sungai Ulin community Health Center with exclusive breastfeeding coverage of only 17.8\% in February 2016 (Health Office of Banjarbaru City, 2016).

Haryani et al. (2014) mentioned that the status of working mothers makes it more difficult for mothers to give breast milk intake to infants. Both in developed and developing countries as well as in Indonesia, working mothers are often faced with a problem, where she has to leave her baby for a certain period. This is because the mother is faced with two choices that are dilemmatic, which is to continue to breastfeed or work to meet economic needs but not to breastfeed regularly or not at all. The results of previous studies conducted by Ariani (2016) in the working area of Sungai Ulin Community Health Center stated that of the 92 mothers sampled in the Sungai Ulin Community Health Center working area, only $11.95 \%$ of working mothers had succeeded in giving exclusive breastfeeding to their babies.

Several factors can affect exclusive breastfeeding. William (2011) explains that these factors include the age of nursing mothers, knowledge and place and birth attendants. Another factor is also explained by Rollins et al. (2016) where one of the several influencing factors is the number of children the mother has or is commonly recognized as parity. 
Based on the description above, it is important to research factors related to the status of exclusive breastfeeding for working mothers in the working area of Sungai Ulin Community Health Center in Banjarbaru City. By doing this research, it is expected to find a solution to overcome the problem of exclusive breastfeeding for working mothers and be a reference to be applied to the broader community, especially in the working area of Sungai Ulin Community Health Center.

\section{RESEARCH METHOD}

This study uses a quantitative method with a cross-sectional design. The population in this study were all working mothers who have babies aged 7 to 12 months in the working area of Sungai Ulin Health Center, Banjarbaru City. The method of sampling in this study was to use random sampling techniques and obtained a total of 61 people. Data were collected using a questionnaire. Univariate analysis using frequency distribution and bivariate analysis using the chi-square test. Analysis continued with multivariate analysis with binary logistic regression analysis.

\section{FINDINGS}

Table 1. Univariate Analysis of Research Variables

\begin{tabular}{|c|c|c|c|}
\hline Variable & Category & Freq & $\%$ \\
\hline Exclusive & $\mathrm{No}$ & 29 & 47.5 \\
\hline Breastfeeding & Yes & 32 & 52.5 \\
\hline Age of Mother & $\begin{array}{l}\text { Ineffective age }(<25 / \geq 35 \\
\text { years }) \\
\text { Effective age }(\geq 25-34 \\
\text { years })\end{array}$ & $\begin{array}{l}29 \\
32\end{array}$ & $\begin{array}{l}47.5 \\
52.5\end{array}$ \\
\hline Knowledge & $\begin{array}{l}\text { Low } \\
\text { High }\end{array}$ & $\begin{array}{l}25 \\
36 \\
\end{array}$ & $\begin{array}{l}41 \\
59 \\
\end{array}$ \\
\hline $\begin{array}{l}\text { Birthplace and } \\
\text { Childbirth } \\
\text { assistance }\end{array}$ & $\begin{array}{l}\text { Not according to standard } \\
\text { According to the standard }\end{array}$ & $\begin{array}{c}1 \\
60\end{array}$ & $\begin{array}{c}1.6 \\
98.4\end{array}$ \\
\hline $\begin{array}{l}\text { Number } \\
\text { children }\end{array}$ & $\begin{array}{l}\text { Primipara } \\
\text { Multipara }\end{array}$ & $\begin{array}{l}25 \\
36\end{array}$ & $\begin{array}{l}41 \\
59\end{array}$ \\
\hline
\end{tabular}

Table 2. Bivariate Analysis with Chi-Square and Fisher Exact

\begin{tabular}{|c|c|c|c|c|c|c|c|c|}
\hline \multirow{3}{*}{ Variable } & \multirow{3}{*}{ Category } & \multicolumn{4}{|c|}{$\begin{array}{c}\text { Exclusive } \\
\text { breastfeeding status }\end{array}$} & \multirow{2}{*}{\multicolumn{2}{|c|}{ Total }} & \multirow{3}{*}{$\begin{array}{l}\text { especially related to the implementation of exclusive } \\
\text { brelfstfeeding Strong estimation, this condition is the cause of the } \\
\text { ressalltrein the study showed that there was no relationship between } \\
\text { the age of breastfeeding mothers with exclusive breastfeeding }\end{array}$} \\
\hline & & \multicolumn{2}{|c|}{ Yes } & \multicolumn{2}{|c|}{ No } & & & \\
\hline & & $\mathbf{N}$ & $\%$ & $\mathbf{N}$ & $\%$ & $\mathbf{N}$ & $\%$ & \\
\hline \multirow[t]{2}{*}{$\begin{array}{l}\text { Age } \\
\text { Mother }\end{array}$} & $\begin{array}{l}\text { Ineffective } \\
\text { age }\end{array}$ & 17 & 58.6 & 12 & 41.4 & 29 & 100 & \multirow{2}{*}{$\begin{array}{l}\text { status. The results of this study are in line with previous studies } \\
\text { condeted by Nurrohmah et al. (2015) with a p-value of } 0.186 \\
\text { (RR: } 0.41) \text {. This result is also similar to the study conducted by }\end{array}$} \\
\hline & Effective age & 12 & 37.5 & 20 & 62.5 & 32 & 100 & \\
\hline \multirow[t]{2}{*}{ Knowledge } & Low & 16 & 64 & 9 & 36 & 25 & 100 & \multirow{2}{*}{$\begin{array}{l}\text { Asemahagn }(2016) \text { where the logistic regression results from the } \\
0.032 \text {, } 34 \text {, } \\
\text { study show that older mothers }(\geq 30 \text { years old) practice exclusive }\end{array}$} \\
\hline & High & 13 & 36.1 & 23 & 63.9 & 36 & 100 & \\
\hline \multirow{2}{*}{$\begin{array}{l}\text { Birthplace } \\
\text { and } \\
\text { childbirth } \\
\text { assistance }\end{array}$} & $\begin{array}{l}\text { Not } \\
\text { according to } \\
\text { standard }\end{array}$ & 1 & 100 & 0 & 0 & 1 & 100 & \multirow{2}{*}{$\begin{array}{l}\text { breastfeeding (OR 2.07) compared to younger mothers }(<30 \\
\text { years). In this study, this was possible because younger mothers } \\
\text { con } \$ \text { 75ered more aesthetic factors such as changes in breast shape } \\
\text { due to breastfeeding caused by breastfeeding with a long duration. } \\
\text { Therefore, they are more likely to give formula milk as a substitute }\end{array}$} \\
\hline & $\begin{array}{l}\text { According to } \\
\text { the standard }\end{array}$ & 28 & 47.5 & 32 & 52.5 & 60 & 100 & \\
\hline \multirow{2}{*}{$\begin{array}{l}\text { Number of } \\
\text { children }\end{array}$} & Primipara & 16 & 64 & 9 & 36 & 25 & 100 & \multirow{2}{*}{$\begin{array}{l}\text { for breast milk } \\
\text { Chi-Square test results on the variable knowledge and exclusive }\end{array}$} \\
\hline & Multipara & 13 & 36.1 & 23 & 63.9 & 36 & 100 & \\
\hline
\end{tabular}

Table 3. Multivariate Analysis

\begin{tabular}{lcccc}
\hline Variable & Sig. & \multirow{2}{*}{$\operatorname{Exp~(B)~}$} & $\frac{\text { 95\% CI }}{\text { Lower Upper }}$ \\
\hline $\begin{array}{l}\text { Age of } \\
\text { Mother }\end{array}$ & 0.009 & 9.115 & 1.725 & 48.176 \\
\hline $\begin{array}{l}\text { Knowledge } \\
\text { Number of } \\
\text { children }\end{array}$ & 0.033 & 3.776 & 1.114 & 12.798 \\
\hline
\end{tabular}

\section{DISCUSSION}

There is no statistically significant relationship between the age of breastfeeding mothers and exclusive breastfeeding status. The two variables are not related can be caused by several factors. Based on data analysis, in the age group of mothers who produce breast milk effectively most of them succeed in implementing exclusive breastfeeding $(62.5 \%)$ which is following the theory of William (2011) where in the age range 25-29 years is the effective period in production ASI and certainly will facilitate the mother in giving ASI. However, in the age group that is not effective for producing breast milk, the ratio of successful and unsuccessful breastfeeding is not too different, which can be concluded that at the age of unproductive mothers, not necessarily mothers are not successful in giving exclusive breastfeeding to their children. If traced further, in 12 respondents with age who were not effective in producing milk but managed to carry out exclusive breastfeeding, 11 of them ( $91.6 \%$ of respondents) were aged $\geq 30$ years. At that age (more than 30 years) the mother's decision to give exclusive breastfeeding can be caused by psychological and social maturity, so that makes a person able to be better in the process of forming his behavior (Notoatmodjo, 2003).

Increasing age also indicates that more time is gained to increase knowledge from existing information and insights, brenstfeeding Strong estimation, this condition is the cause of the PR Strong estimation, this condition is the cause of the rasalltre in the study showed that there was no relationship between status. The results of this study are in line with previous studies condereted by Nurrohmah et al. (2015) with a p-value of 0.186 
results of this test are also supported by a high PR value of 3.13, which means that a high level of knowledge about exclusive breastfeeding will increase opportunities for exclusive breastfeeding by 3.14 times greater than at low levels of knowledge related to exclusive breastfeeding. The results of this study are following the theory described by Notoatmodjo (2003), where knowledge can play an important role in shaping one's actions (overt behavior). The knowledge possessed is basically the result of knowing someone after the person senses. In this case, the person who knows more about exclusive breastfeeding and its benefits will do more seriously so that it is carried out well. In particular, groups of working mothers, who are often exposed to education and information, one of which can be related to exclusive breastfeeding will increase their knowledge and be directly proportional to the implementation of exclusive breastfeeding. This is supported by the table where respondents with a high level of knowledge have a tendency to implement exclusive breastfeeding (63.6\%). The results in this study are in line with previous studies conducted by Nkala and Msuya et al. (2011), which found an association between adequate knowledge about exclusive breastfeeding and the implementation of exclusive breastfeeding in mothers of reproductive age. The results of other studies conducted by Wen et al. (2009) showed that mothers who knew information related to exclusive breastfeeding following recommendations from $\mathrm{WHO}$ had a 5 times greater chance of implementing exclusive breastfeeding compared to mothers who did not know the information.

The fisher exact test results on the place variables and birth attendants with exclusive breastfeeding status obtained p-value 0.475 , which can be interpreted to find no statistically significant relationship between the place and birth attendants with exclusive breastfeeding status. The results obtained in this study are also similar to the research conducted by Novitasari et al. (2019), which states that there is no relationship between the place and birth attendant with exclusive breastfeeding behavior. The absence of a relationship between the 2 variables can be understood because in the table, there are large data differences between categories, where there is only 1 respondent whose place and helper are not in accordance with the standard and the remaining 60 respondents according to the standard. On the one hand this is a positive finding where almost all respondents have realized that delivery in a health facility and assisted by health workers will better guarantee the success of delivery. However, the same table also shows that the comparison between respondents whose place and birth attendants are in accordance with the standards that implement exclusive breastfeeding and not implement exclusive breastfeeding is only slightly, namely $52.5 \%$ (32 people) and $47.5 \%$ (28 people). Field facts show that of the 28 people whose birth attendants and helpers are in accordance with the standards, 21 of them stated that they received advice from childbirth assistance in relation to exclusive breastfeeding but were unable to carry it out, and 7 others stated that there was no advice from birth attendants regarding exclusive breastfeeding and only recommended for early breastfeeding initiation.

The findings of 7 people who did not get recommendations related to the implementation of exclusive breastfeeding indicate that health services (in terms of place and health personnel) are still not optimal enough for the successful implementation of exclusive breastfeeding. These two factors should play an important role, but because the duration of the mother who is in the delivery place is only 2-3 days, an explanation of breastfeeding, breast care and guidelines for the implementation of exclusive breastfeeding can not be conveyed properly. Health workers mostly focus on other things, such as postpartum management. This can be one of the other factors that can affect the role of health workers and health facilities not yet related to exclusive breastfeeding (Wulandari and Handayani, 2011).

Chi-Square test results on the variable number of children and exclusive breastfeeding obtained p-value 0.032 , which can be interpreted that there is a statistical relationship between the number of children with exclusive breastfeeding status. This result is also supported by a large PR of 3.14 , where the value can be interpreted that mothers with multipara will increase the chance for exclusive breastfeeding by 3.14 times greater than in mothers with primipara. This relates to the experience of mothers, where mothers with multiparas certainly have better experience in handling babies compared to mothers who first give birth. Experience has an important role for a mother to do exclusive breastfeeding and becomes the basis for further behavior (Fikawati and Syafiq, 2011). If in the previous birth, the mother succeeded in carrying out exclusive breastfeeding, then the basis of the previous experience will be reflected in the conditions afterward (Rollins, 2016).

The relationship between the 2 variables was found to be understood because 25 primiparous mothers, most of them tended not to implement exclusive breastfeeding (16 people or $64 \%$ ) and those with multiparous women were more likely to successfully implement exclusive breastfeeding (23 out of 36 respondents or $63.9 \%$ ). Field facts show that multiparous mothers already have the experience to care for their children. As many as 17 of the 23 respondents stated that they succeeded in implementing exclusive breastfeeding from the previous child and the remaining 6 respondents stated that they failed to implement exclusive breastfeeding in the previous child but were successful in giving it to the last child. A total of 8 respondents from 23 multipara respondents who succeeded in implementing exclusive breastfeeding stated that the way they carry out exclusive breastfeeding is by preparing reserves of breast milk before work, preparing breast milk when he works by storing milk supply at home (pumping milk and storing it in bottles) and then when returning from work. The rest 15 of the 23 respondents stated that they brought their children to work and gave breastfeeding there, of which all respondents work as entrepreneurs

The above results are also in accordance with the explanation of Rollins et al. (2016), where mothers who fail to breastfeed are less likely to try breastfeeding in the next pregnancy, which means this will directly affect the status of exclusive breastfeeding. Mothers have a higher chance of repeating the feeding decision that has been made on the first child for the next child. That is, those who breastfeed in the first baby tend to breastfeed in the next child, and for mothers who do not breastfeed their firstborn, they are less likely to breastfeed the next baby (Vanzo, 1991). This is in line 
with research conducted by Becerra and Smith (1990) which found that mothers who breastfed a previous baby were 7.3 times more likely to breastfeed their next baby compared to mothers who had not previously breastfed a baby. Research conducted by Nagy et al. (2001) also get the same result where previous breastfeeding experiences can influence mothers in regulating the duration of the next breastfeeding to the optimal level for them, namely exclusive breastfeeding.

The variable number of children has the largest $\operatorname{Exp}(B)$ value of 11.049 that mothers with multipara tend 11.049 to give exclusive breastfeeding compared to mothers with primipara. The number of children is broadly related to the mother's experience in childcare. Someone who has the history or previous experience to take care of their children will certainly get lessons, both in a positive sense (such as being able to properly care for children, provide good nutrition and according with age) and vice versa, and have the opportunity to maintain or improve it in a better direction.

In addition to the number of children, factors related to exclusive breastfeeding status based on multivariate testing are the age and knowledge of mothers. This condition can be understood because the interaction of the 3 factors above will shape the mother's experience in the management and implementation of exclusive breastfeeding. The track record, lessons and techniques obtained by mothers from breastfeeding children before, as well as the ideal age for producing milk will greatly support and facilitate the implementation of exclusive breastfeeding.

The experience described above relates to the successful implementation of exclusive breastfeeding for working mothers, where mothers have a double workload, namely as workers and mothers for their children. Colombo et al. (2018) explained that the obstacles that arise in the implementation of exclusive breastfeeding, such as the limited area of breastfeeding in public areas, limited time due to work, social support and work colleagues and workload (Ishola, et al. 2019). In handling the problem above, the statistical analysis has discussed that most working mothers are able to carry out exclusive breastfeeding, and this success can be caused by the mother knowing how to manage the time and methods related to breastfeeding, that is, before working, preparing ASI when she works by storing milk supply at home (pumping milk and storing it in a bottle) and then when returning from work. Some respondents also stated that they brought their children to work and did breastfeeding there. The ease of mother in implementing this is certainly supported by effective age in producing breast milk and also mother's knowledge about breast milk. This description is in accordance with the results of previous studies conducted by Poduval and Poduval (2009) where when working mothers who give birth and return to work after leave tendency will not change their commitment to the implementation of exclusive breastfeeding but will adjust the method, duration and time for breastfeeding.

Research Wardani et al. (2017) explain that there is a concurrent relationship between age and parity. Other studies by Kitano et al. (2016) also found that there was a strong relationship between parity and age with exclusive breastfeeding. In line with this, Mabud et al. (2014) in his study, stated that there is a relationship between parity (number of births) and exclusive breastfeeding. Parity is very influential on one's acceptance of something. The more mother's experience, the acceptance of exclusive breastfeeding will be easier. The mother will make the experience as a source of learning to make improvements and solve problems previously encountered. Another study conducted by Tan (2011) explained that mothers with multiparas were almost twice as likely to give exclusive breastfeeding compared to primiparous due to their experience factors.

The results in this study indicate that 12 out of 23 people $(52.2 \%$ of respondents) multipara respondents who successfully implemented exclusive breastfeeding were mothers with 2 children. The same thing was also found in the research of $\mathrm{Da}$ Vanzo, et al. (1990) in mothers with at least 2 children who showed that the decision most frequently chosen by mothers was to repeat the breastfeeding decisions they made with the first child. That is, in mothers who breastfeed their first child it is possible to breastfeed the next child, conversely in mothers who do not breastfeed their first child or experience breastfeeding done by mothers with short duration (less than 6 months), is considered unsuccessful, or unsatisfactory then the tendency will not or there is very little chance of feeding the child afterward. If this is related to the results obtained in this study, where mothers who have more than 1 child, with a productive age, produce breast milk and good knowledge about breast milk, mothers can implement exclusive breastfeeding successfully.

\section{CONCLUSION}

Based on research that has been done in the working area of Sungai Ulin Community Health Center in Banjarbaru City, it can be concluded that there is a relationship between knowledge ( $\mathrm{p}$ value 0.032 ) and the number of children (p-value 0.032 ), while the age of breastfeeding mothers (p-value 0.099) and the place and birth attendants $(0.475)$ show no relationship with exclusive breastfeeding status. The multivariate results show that the number of children is the variable most dominant related to the status of exclusive breastfeeding with a p-value of 0.002 and Exp (B) 11.069 times the impact on the status of exclusive breastfeeding.

It is recommended that the Community Health Center be able to give more attention to working mothers who give birth or have children for the first time in order to become the primary target in counseling programs and individual counseling in the hope that the mother becomes more alert and knows information about exclusive breastfeeding and how to practice breastfeeding exclusively during work. 


\section{REFERENCES}

Ariani, UA 2016. Relationship between Mother's Education Level, Family Income, Colostrum Smoothness and Working Mother Status with Exclusive Breastfeeding. Thesis. Lambung Mangkurat University. Banjarbaru.

Asemahagn MA. 2016. Determinants of exclusive breastfeeding practices among mothers in Azezo district, Northwest Ethiopia. Int Breastfeed J. 11 (22).

Banjarbaru City Health Office. 2016. Recapitulation of Exclusive Breastfeeding in August 2016. Banjarbaru.

Becerra, JE, Smith, JC 1990. Breastfeeding Patterns in Puerto Rico. Am J Public Health Journal. 80 (6); 694-697.

Colombo, L., Crippa, BL., Consonni, D., Bettinelli, ME., Agosti, V., Mangino, G., Bezze, EC., Mauri, PA., Zanotta, L., Rogerro, P., Plevani, L., Bertoli, D., Gianni, ML., Mosca, F. 2018. Breastfeeding Determinants in Healthy Term Newborns. Nutrients Journal . 10 (48).

Da Vanzo J, Starbird E, Leibowitz A. 1990. Do women's breastfeeding experiences with their first-born affects whether they breastfeed their subsequent children? . Soc Biol . 37; 223-32.

Fikawati, S., Syafiq, A. 2009. Causes of the Success and Failure of the Practice of Exclusive Breastfeeding. National Journal of Public Health. 4 (3); 120-131.

Haryani. 2014. Reasons for Not Given Exclusive ASI by Working Mother in the City of Mataram, West Nusa Tenggara. Thesis. Udayana University. Denpasar.

Ishola, AA., Adekunle, KA., Temitope, AF. 2019. Social-Demographic Factors Influencing Exclusive Breastfeeding Attitude among Working Nursing Mothers in Urban Areas Of Ibadan, Oyo State. Psychological Research on Urban Society . 2 (2); 76-87.

Kitano, N., Nomura, K., Kido, M., Murakami, K., Ohkubo, T., Ueno, M., Sugimoto, M. 2016. Combined Effects of Maternal Age and Parity on Successful Initiation of Exclusive Breastfeeding. Preventive Medicine Reports . 3; 121-126.

Mabud, NH., Mandang, J., Mamuaya, T. 2014. Relationship of knowledge, education, parity with exclusive breastfeeding at the Community Health Center Malalayang District, Manado City. Midwife Scientific Journal. 2 (2); 51-56.

Ministry of Health Republic of Indonesia. 2016. Indonesian Health Profile 2015. RI Ministry of Health. Jakarta.

Ministry of Health Republic of Indonesia. 2017. Indonesia Health Profile 2016. RI Ministry of Health. Jakarta.

Ministry of Health Republic of Indonesia. 2018. Indonesian Health Profile 2017. RI Ministry of Health. Jakarta.

Nagy, E., Orvos, H., Pal, A., Kovacs, L., Loveland, K. 2001. Breastfeeding duration and breastfeeding experience. Acta Pediatr Journal. 90; 51-56.

Nkala, TE and Msuya, SE 2011. Prevalence and predictors of exclusive breastfeeding among women in the Kigoma region, Western Tanzania: a community-based cross-sectional study. International Breastfeeding Journal. 6 (17) .

Notoatmodjo, S. 2003. Health Education and Behavior . Jakarta: Rineka Cipta.

Novitasari, Y., Mawati, ED and Rachmania, W. 2019. Factors related to exclusive breastfeeding behavior at the Tegal Gundil Health Center in Bogor, West Java in 2018 . Journal Promoter. 2 (4); 324-333.

Nurrohmah, A., Prawitasari, S., Nisman AW 2015. Role of mother support group (KP-Ibu) on behavior of exclusive breastfeeding in work area of primary health care (Community Health Center) of Ngoresan Surakarta. International Journal of Research in Medical Sciences. 3 (1); S85-S91.

Poduval, J., and Poduval, M. (2009). Working mothers: how much work, how much mothers, and where is womanhood ?. Menssana monographs. 7 ; 63-79.

Rollins, NC., Bhandari, N., Hajeebhoy, N., Horton, S., Lutter, CK, Martines, JC Piwaz., EG, Richter, LM, Victora, CG and The Lancet Breastfeeding Series Group. 2016. Why Invest, and What Will It Take to Improve Breastfeeding Practices? Lancet Editorial Series. 387 (2); 491-504.

South Kalimantan Provincial Health Office (Dinkes). 2018. Nutrition Program Annual Report: Achievement of Exclusive ASI in South Kalimantan 2012 - 2017 Banjarmasin.

Tan, KL 2011. Factors associated with exclusive breastfeeding among infants under six months of age in Malaysian peninsular. Int Breastfeeding Journal. 6 (2); $1-7$

Vanzo, JD, Starbird, EH 1991. Correlates of Short Interbirth Intervals in Peninsular Malaysia: Their Pathways of Influence Through Breastfeeding and Contraceptive Use. Studies in Family Planning Journal. 22 (4); 241-254.

Wardani, EK., Hastuti, URB., Adriani, RB. 2017. Relationship between Sociodemographic Factors and Mother Participation in the Breast Feeding Support Group with Exclusive Breastfeeding Success in Banyuwangi. Journal of Maternal and Child Health . 2 (4); 335-344.

Wen LM, Baur LA, Rissel C, Alperstein G, Simpson JM. 2009. Intention to breastfeed and awareness of health recommendations: findings from first-time mothers in southwest Sydney, Australia. International Breastfeeding Journal. 4 (9).

WHO. 2009. Infant and Young Child Feeding: Model Chapter for Textbooks for Medical Students and Allied Health Professionals. France: WHO Press.

William, T . B. 2011. Combination formula/breastfeeding and the newborn. St Louis Missouri: Mosby Publishing Co

Wulandari, SR., Handayani, S. 2011. Midwifery care for postpartum mothers. Yogyakarta: Gosyen Publishing.

\section{AUTHORS}

First Author - Erni Wiliyani ZM, Master of Public Health, Faculty of Medicine, Lambung Mangkurat University, Indonesia. Second Author - Roselina Panghiyangani, Department of Biomedicine, Faculty of Medicine, Lambung Mangkurat University, Indonesia.

Third Author - Lenie Marlinae, Public Health Study Program, Faculty of Medicine, Lambung Mangkurat University, Indonesia. Fourth Author - Husaini, Master of Public Health, Faculty of Medicine, Lambung Mangkurat University, Indonesia.

Fifth Author - Meitria Syahadatina Noor, Department of Public Health, Faculty of Medicine, Lambung Mangkurat University, Indonesia.

Correspondence Author - Erni Wiliyani ZM, Master of Public Health, Faculty of Medicine, Lambung Mangkurat University, Indonesia, email: ayizm.pubhealth@gmail.com 